\title{
Study of Blend of Extracts from Bitter Leaf (Vernonia Amygdalina) Leaves and Banana (Musa Acuminata) Stem as Corrosion Inhibitor of Mild steel in Acidic Medium
}

\author{
K. F. Oyedeko, M. K. Lasisi, and A. S. Akinyanju
}

\begin{abstract}
This study investigates the effect of concentration of different ratio of the leaves extracts Bitter leaf (Vernonia amygdalina) and Banana stem (Musa Acuminata) on corrosion of mild steel in acidic medium using weight loss method at different temperatures $(303 \mathrm{~K}$ to $323 \mathrm{~K})$ to determine the inhibitory potentials of the extracts. The FTIR and SEM were used to determine the functional groups and morphology of the mild steel respectively during the experiment. The results showed that the inhibition efficiency (IE) increased with an increase in the concentration of the inhibitor $(0.1 \mathrm{~g} / \mathrm{l}$ to $0.5 \mathrm{~g} / \mathrm{l})$ but decreased with an increase in temperature $(303 \mathrm{~K}$ to $323 \mathrm{~K})$ for all the ratios of bitter leaf and banana stem extracts used. The results also showed that the inhibition efficiency increases with an increase in the concentration and shows maximum inhibition efficiency of $(80.85 \%)$ at optimum concentration $(0.5 \mathrm{~g} / \mathrm{L})$ The Energy Dispersive X-ray Spectroscopy (EDS) spectra of the mild steel showed that the composition of Carbon and Oxygen increased by $4 \%$ and $24.31 \%$, respectively. The increase might probably be attributed to the presence of $\left(\mathrm{CH}_{2}\right)$ in $\mathrm{CH}_{2} \mathrm{OH}$ group. The presence of cavities and pits in the Scanning Electronic Microscope (SEM) images of mild steel showed the damages on the mild steel by corrosion medium. The corrosion rate of mild steel in $1 \mathrm{M} \mathrm{HCl}$ decreased with an increase in the concentration of the extracts for the different concentrations of extracts used, $100 \%$ bitter leaf extract (BLE) has the highest corrosion inhibitory efficiency; this was closely followed by 1:4 blends of bitter leaf extract (BLE) and banana extract (BNE). $100 \% \mathrm{BNE}$ extract has the lowest inhibitory efficiency for the different ratios of extracts concentration used. Bitter leaves extracts have better inhibitory efficiency than Banana stem extracts.
\end{abstract}

Keywords - Banana stem, Blend extract, Bitter leaves, Corrosion rate, Inhibition efficiency.

\section{INTRODUCTION}

Corrosion is an inevitable electrochemical process that causes degradation of any material in particular environment, that affects the performance of metals especially those that are used in the process industry and construction that is in contact with acid [1], [2].

Submitted on December 24, 2021.

Published on January 25, 2022.

K. F. Oyedeko, Department of Chemical Engineering, Lagos State University, Lagos, Nigeria.

(e-mail: kfkoyedeko@yahoo.com)

M. K. Lasisi, Department of Chemical and Petroleum Engineering, University of Lagos, Nigeria.

(e- mail: mosunmola.lasisi@gmail.com)

A. S. Akinyanju, Department of Chemical and Petroleum Engineering, University of Lagos, Nigeria

(e-mail: aadewale777@gmail.com)
The important economic life is affected by the pervasive nature of corrosion and hence catastrophic effect on the general development as corrosion in various degradation is found in many spheres of life and industries such as oil and gas, automobile, steel, shipping, aircraft, construction, transport, defense, electrical/electronic, etc. [2]-[4].

The study of mild steel (MS) corrosion phenomena has become important particularly in acid media because of the increased industrial applications of acid solutions [5]. Consequently, the need to control corrosion of mild steel continues to be a major concern to the engineer as a failure of various kinds may occur and expensive replacements are required even though the amount of metal destroyed may be small. Since corrosion is impracticable to eliminate, effective corrosion science and engineering lie in controlling rather than preventing it [2], [6]. An attractive way of combating corrosion is the use of corrosion inhibitors [7]. Corrosion inhibitors are substances that when added in small quantities to a corrosive environment lower the corrosion rate by either acting as a barrier by forming an adsorbed layer or retarding the cathodic and/or anodic process [3].

Sequel to increasing awareness and strict environmental regulations of toxic nature and high cost of some of these inhibitors, corrosion inhibitors derived from plant extract that are biodegradable and do not contain heavy metals or other toxic compounds are preferable [8]. Extract of various plants have been investigated and reported by several authors as having the potentiality to reduce metal dissolution in various aggressive acids for use as green inhibitor such as Azadirachita indica, carica papaya, guar gum, opuntiaficus indica, delonix regia etc. [9]-[12]. The extract of these plants as well as the corrosion inhibition abilities efficiency vary widely depending on the part of the plant and its geographical location.

This is justified by the phytochemical analysis carried to determine the compounds present therein with molecular and electronic structures with other close similarity to conventional organic inhibitor molecules [13].

Bitter leaf plant (Vernonia amygdalina) is one of the commonly available plants in most parts of the tropical nations in Africa and Asia. Its extracts have been reported to have inhibitory effect on mild steel [14], [15]. It is also known to contain tannin, among others, which has been variously associated with corrosion inhibition in the aqueous and acidic environment [6], [16].

This study investigates the inhibition effectiveness of extract from Bitter leaf (Vernonia amygdalina) and Banana stem (Musa Acuminata) in $1 \mathrm{M} \mathrm{HCl}$ on mild steel as environmentally friendly corrosion inhibitors using weight loss method with different ratios and concentration of Bitter 
leaf (Vernonia amygdalina) and Banana stem (Musa Acuminata) extract, with the effect of temperature on corrosion of mild steel.

\section{MATERIALS AND METHODS}

\section{A. Materials}

Mild steel, bitter leave, banana stem. Reagent used, $\mathrm{HCl}$, Ethanol, Acetone, Distilled water

\section{1) Apparatus/Equipment}

Electronic weighing balance, fourier transform infrared spectroscopy (FTIR), the equipment used to study the morphology of mild steel is Joel scanning electronic microscope (SEM) with model JSM 7600F., energy dispersive x-ray specroscopy (EDS), measuring cylinder, timble, oven, water bath, soxhlet extractor, heating mantle, sieves, sample bottles, electronic miller, trays, paper tape, nose mask, marker.

\section{B. Method}

\section{1) Preparation of metal specimen}

The mild steel was cut into 51 various pieces of the same measured dimensions $3 \mathrm{~mm}$ thickness, length $26 \mathrm{~mm}$, breath $17 \mathrm{~mm}, 1$ piece was used to obtain the percentage composition, the other 50 pieces were then ground with abrasive sand paper to remove debris on the mild steel after which it was rinsed with analytical ethanol. Acetone was used to remove any oil or grease particles on the steel. After drying the specimens were labeled, then put in the oven at $40{ }^{\circ} \mathrm{C}$, the specimens were cooled and weighed to obtain their initial weights. The prepared mild steel should be kept in desiccators to prevent dust from dropping on it and then used for the experiment immediately after preparation [15].

\section{2) Preparation of bitter leaf and banana stem (powder form)}

Bitter leaf was plucked from its tree in the garden on campus. It was washed and dried in the oven at $45^{\circ} \mathrm{C}$ for 1 day after which the drying temperature was increased to $105^{\circ} \mathrm{C}$ for 48 hours. Banana stem was gotten from a Farm on campus. It was cut into pieces, washed and sand particles and stones removed from it. It was dried under the sun for 2 days so as to reduce the moisture content to an appreciable level and further subjected to drying in a standard oven at $105^{\circ} \mathrm{C}$ for 72 hours. The dried bitter leave and banana stem were milled separately into powder form. The powdered bitter leaf and banana stem were sieved separately with a $10 \mathrm{~mm}$ mesh size sieve so as to obtain a fine particle. The fine particles were stored separately in an airtight jar and placed inside the desiccators [15].

\section{3) Preparation of plants extracts (corrosion inhibitor)}

Two grams ( $2 \mathrm{~g}$ ) of the milled bitter leave and banana stem were packed inside a timble. This was loaded into the feed compartment of a $500 \mathrm{ml}$ soxhlet extractor. About $250 \mathrm{ml}$ of analytical grade ethanol was poured inside the soxhlet extractor flask and placed on a regulated heating mantel. The extraction was carried out at a heating temperature of $80{ }^{\circ} \mathrm{C}$ for 6 hours so as to have total extraction of the entire component inside the plants. The extraction process was carried out on different ratios of the plant mixture and it was stored separately. After the extraction process was complete, the extracts were subjected to evaporation so as to remove the ethanol and obtain a pure liquid of the extracts. The pure extracts were stored in well labeled sample bottles and placed inside the fridge for further use.

\section{4) Corrosion inhibition of mild steel}

$1 \mathrm{M}$ of $\mathrm{HCl}$ was prepared inside a volumetric flask using distilled water. $100 \mathrm{ml}$ of the prepared $\mathrm{HCl}$ was measured into 10 beakers and placed inside a water bath. $10 \mathrm{ml}$ of the plant extracts were added to each of the beakers. A weighed mild steel sample was placed inside each of the beakers. At 1 hour intervals, the mild steel was removed from the beaker and weighed. The new weight was recorded, and this process was carried out at different temperatures.

\section{5) Weight loss (WL) measurement}

The mild steel samples were retrieved at 1-hour intervals progressively for 30 days. After each exposure time, the steel was removed, cleaned with analytical acetone, and dried thoroughly to remove the corrosion product (Rust Stain) with a piece of clean cotton cloth. The steel was reweighed to determine the weight loss, in grams by the difference of steel weight before and after immersion. Weight loss was determined by calculating the difference between the weight of each steel sample before and after immersion.

$W=W_{b}-W_{a}$

where $\mathrm{W}$ is weight loss, $\mathrm{W}_{\mathrm{b}}=$ weight of Steel Sample before immersion, $\mathrm{W}_{\mathrm{a}}=$ Weight of steel sample after immersion.

\section{6) Determination of corrosion rate}

The corrosion rate $(\mathrm{CR})$ in the absence and presence of inhibitors was calculated using equation (2).

The corrosion rate $(\mathrm{CR})$ in $\mathrm{mm} /$ year:

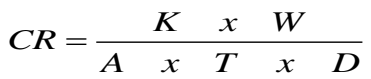

where, $W=$ weight loss $(\mathrm{g}), K=$ corrosion rate constant $=8$. $76 \times 10^{4}, A=$ area of specimen $\left(\mathrm{cm}^{2}\right), D=$ density of Steel $\left(\mathrm{g} / \mathrm{cm}^{3}\right)=7.86 \mathrm{~g} / \mathrm{cm}^{3}, \mathrm{~T}=$ time of exposure in hours $=24$ hours,

$\mathrm{W}$ is the weight loss $(\mathrm{g})$ after exposure time $\mathrm{t}, \mathrm{A}$ is the area of the specimen $\left(\mathrm{cm}^{2}\right), \mathrm{t}$ is time of exposure in hours and $\mathrm{CR}_{\mathrm{o}}$ is the corrosion rate of mild steel without inhibitor, while $\mathrm{CR}_{1}$ is the corrosion rate of mild steel with inhibitor.

Inhibition Efficiency (IE \%) was calculated using equation (3) [15]:

$$
I E(\%)=\frac{\text { Weight loss without inhibitor }- \text { Weight loss with inhibitor }}{\text { Weight loss without inhibitor }} \times 100
$$

Surface coverage $\theta$ was calculated by using the following formula [15].

$\theta=\frac{\text { Weight loss without inhibitor }- \text { Weight loss with inhibitor }}{(4)}$ 


\section{RESUlTS AND DISCUSSION}

The results of corrosion rate, inhibition efficiency and surface coverage for $0.1 \mathrm{~g} / \mathrm{l}$ to $0.5 \mathrm{~g} / \mathrm{l}$ extracts at $303 \mathrm{~K}$ to $323 \mathrm{~K}$. are shown in Fig. 1 to 12 . The corrosion rate decreases with time for different ratios of extracts. The behavior is attributed to a higher adsorption level of active inhibitor molecules from the extracts on the metal surface forming a thin film on metal surface to prevent further attack from the corrosive environment, thereby reducing weight loss by specimen. Also, it is noted that the inhibition efficiency depends on temperature and decreases with the rise of temperature, indicating that at the higher temperature, dissolution of mild steel predominates on the surface. which are in agreement with the findings of previous researchers [6], [17]-[18].

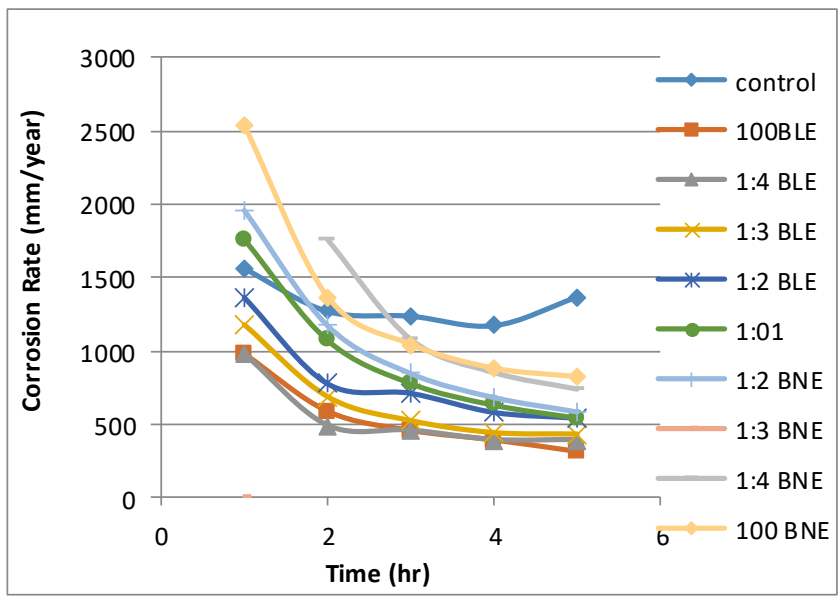

Fig. 1. Graph of corrosion rate vs time for $0.1 \mathrm{~g} / \mathrm{l}$ inhibitor concentration at $30^{\circ} \mathrm{C}$.

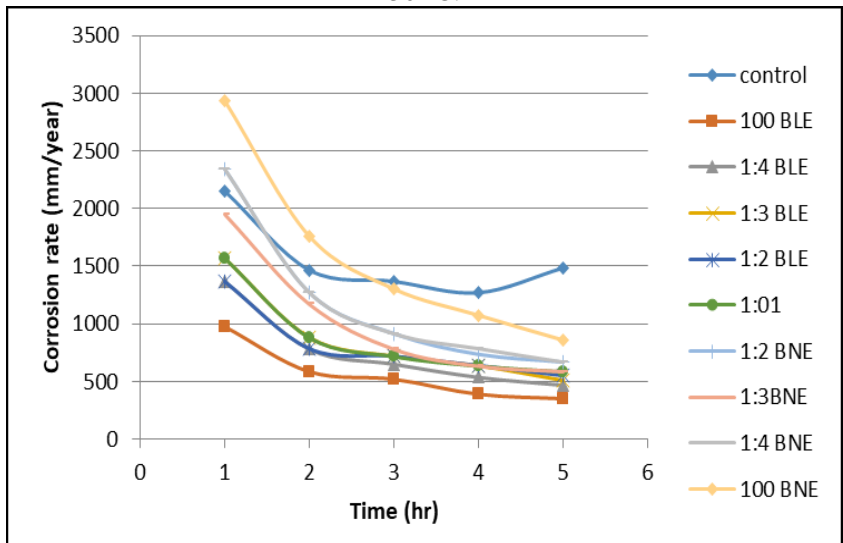

Fig. 2. Graph of corrosion rate vs time for $0.1 \mathrm{~g} / \mathrm{l}$ inhibitor concentration at $40{ }^{\circ} \mathrm{C}$

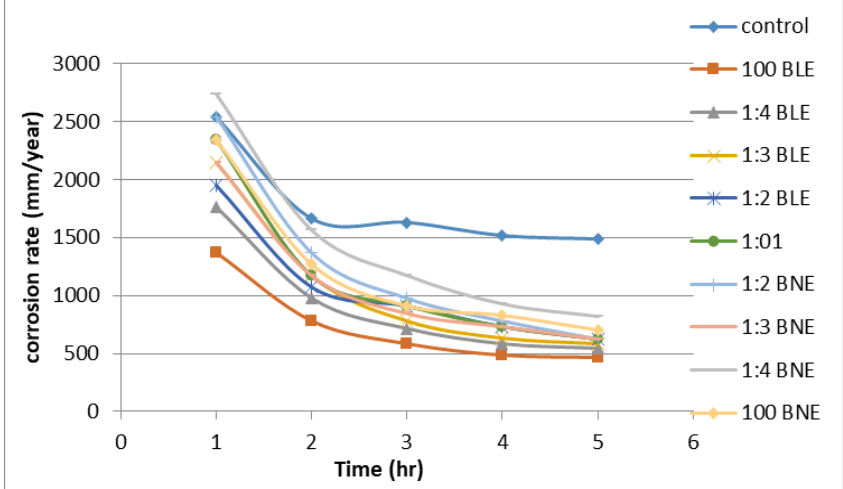

Fig. 3. Graph of corrosion rate vs time for $0.1 \mathrm{~g} / \mathrm{l}$ inhibitor concentration at $50{ }^{\circ} \mathrm{C}$.

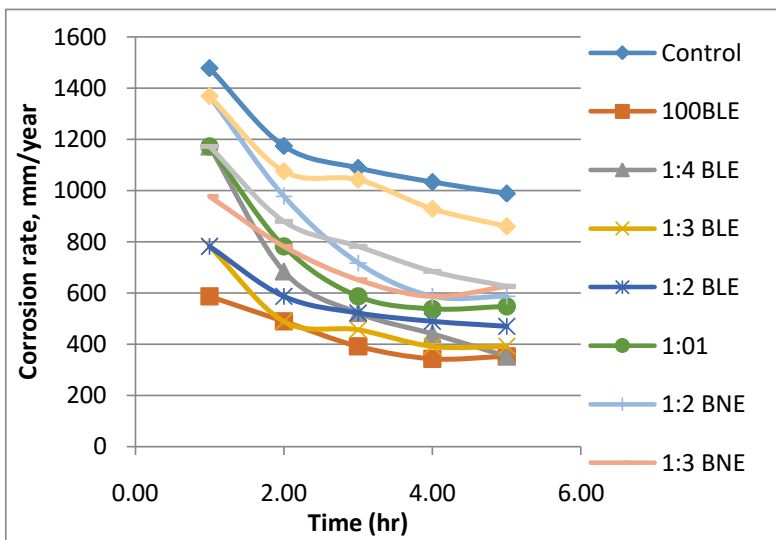

Fig. 4. Graph of corrosion rate vs time for $0.3 \mathrm{~g} / \mathrm{l}$ inhibitor concentration at $30{ }^{\circ} \mathrm{C}$.

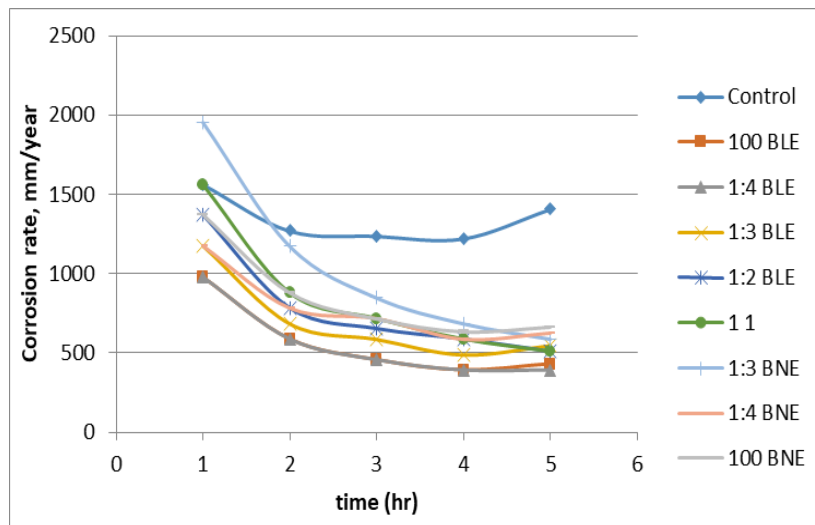

Fig. 5. Graph of corrosion rate vs time for $0.3 \mathrm{~g} / \mathrm{l}$ inhibitor concentration at $40^{\circ} \mathrm{C}$

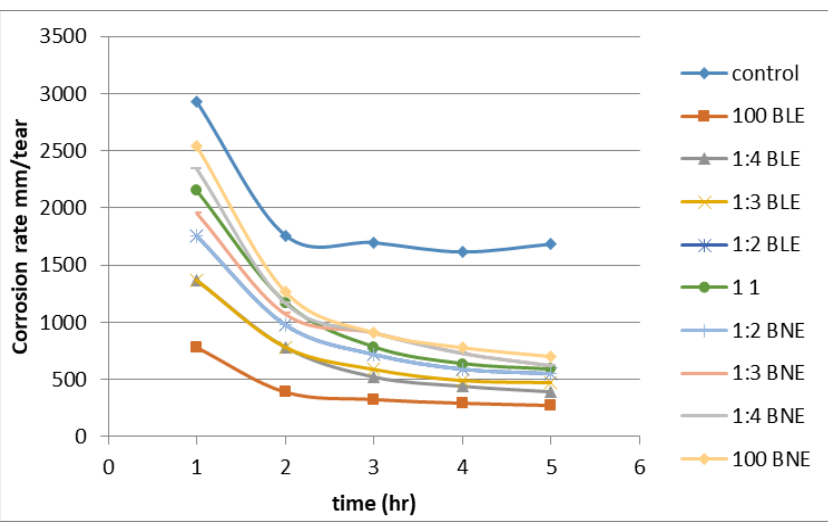

Fig. 6. Graph of corrosion rate vs time for $0.3 \mathrm{~g} / \mathrm{l}$ inhibitor concentration at $50{ }^{\circ} \mathrm{C}$

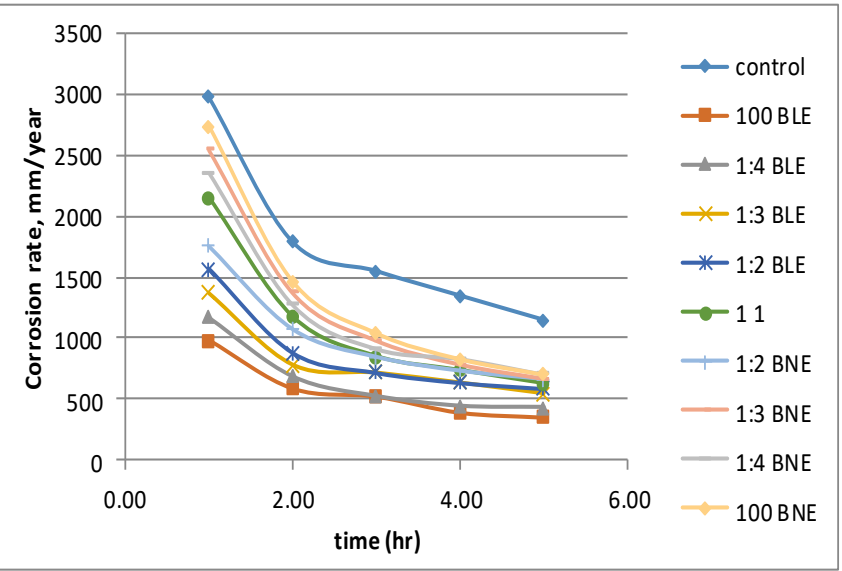

Fig. 7. Graph of corrosion rate vs time for $0.5 \mathrm{~g} / \mathrm{l}$ inhibitor concentration at $30{ }^{\circ} \mathrm{C}$. 


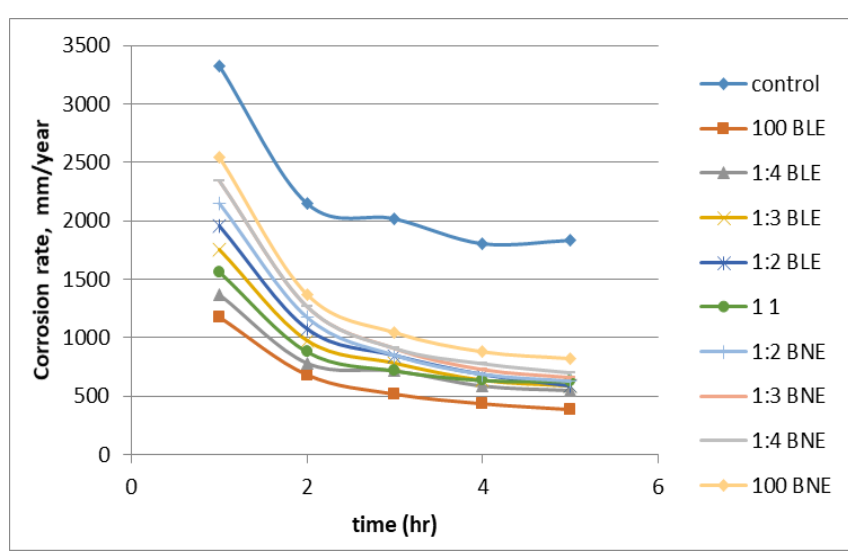

Fig. 8. Graph of corrosion rate vs time for $0.5 \mathrm{~g} / \mathrm{l}$ inhibitor concentration at $40{ }^{\circ} \mathrm{C}$.

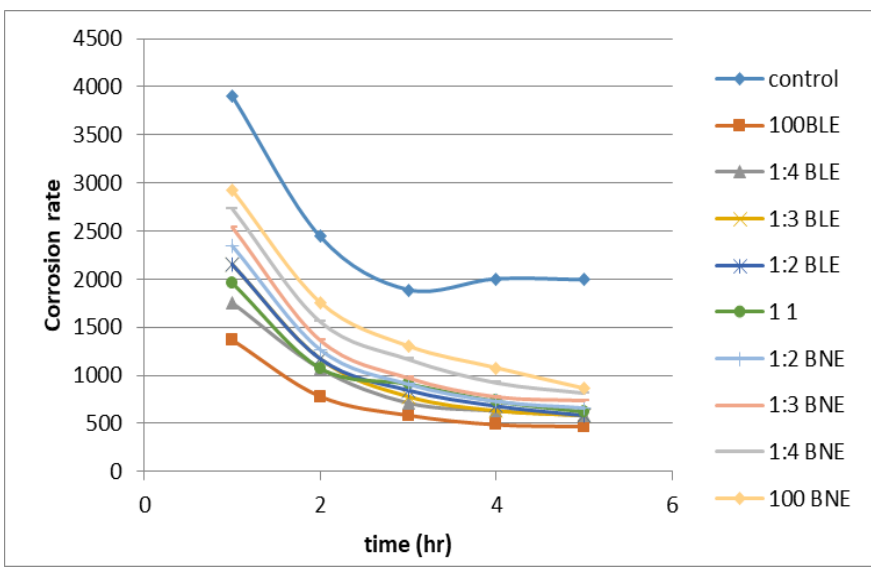

Fig. 9. Graph of corrosion rate vs time for $0.5 \mathrm{~g} / \mathrm{l}$ inhibitor concentration at $50^{\circ} \mathrm{C}$.

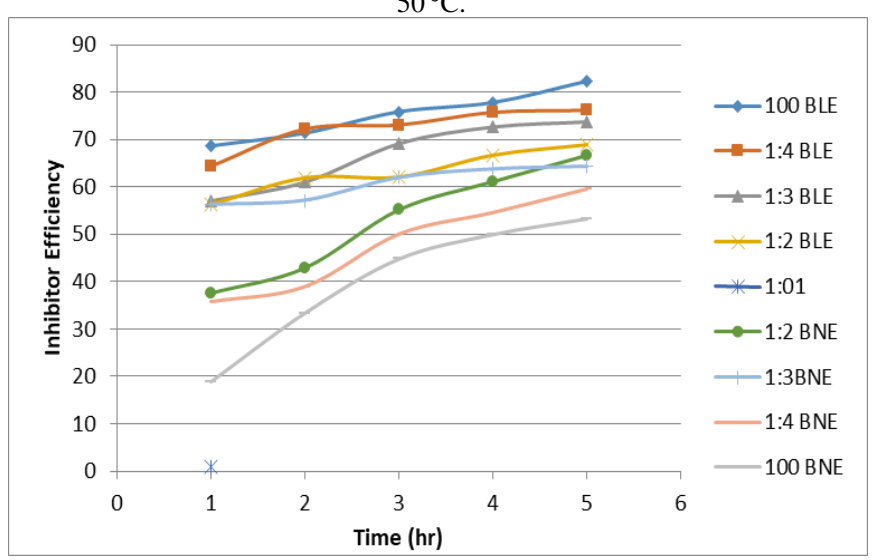

Fig. 10. Graph of Inhibitor efficiency vs time for $0.1 \mathrm{~g} / \mathrm{l}$ inhibitor concentration at $30^{\circ} \mathrm{C}$

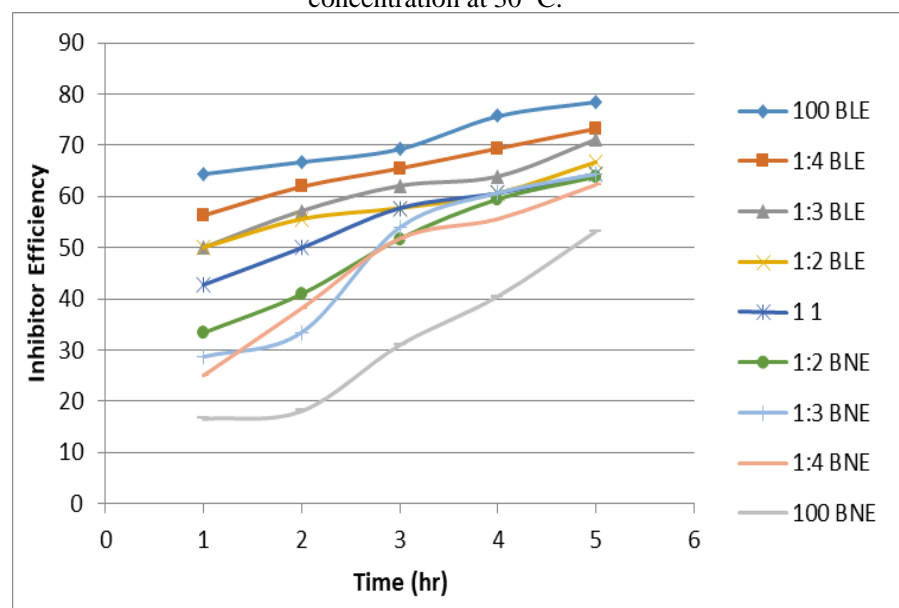

Fig. 11. Graph of Inhibitor efficiency vs time for $0.1 \mathrm{~g} / \mathrm{l}$ inhibitor concentration at $40^{\circ} \mathrm{C}$.

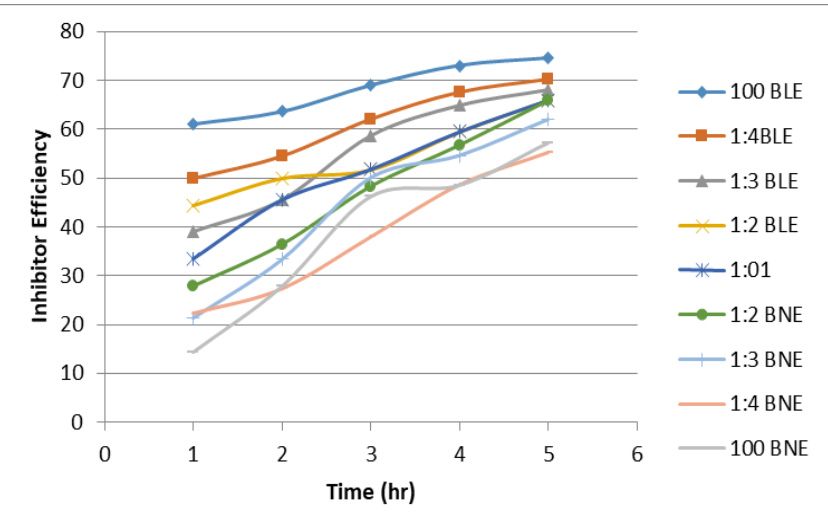

Fig. 12. Graph of Inhibitor efficiency vs time for $0.1 \mathrm{~g} / \mathrm{l}$ inhibitor concentration at $50{ }^{\circ} \mathrm{C}$.

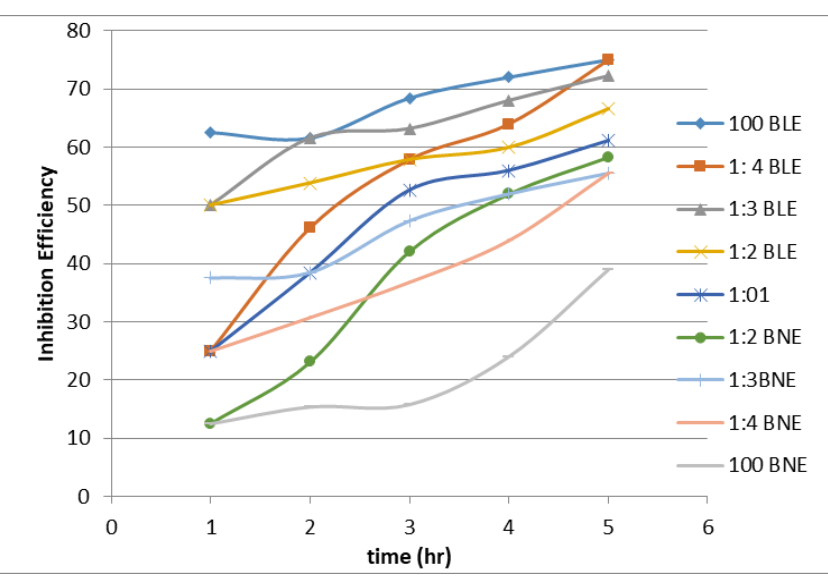

Fig. 13. Graph of Inhibition efficiency vs time for $0.3 \mathrm{~g} / \mathrm{l}$ inhibitor concentration at $30^{\circ} \mathrm{C}$.

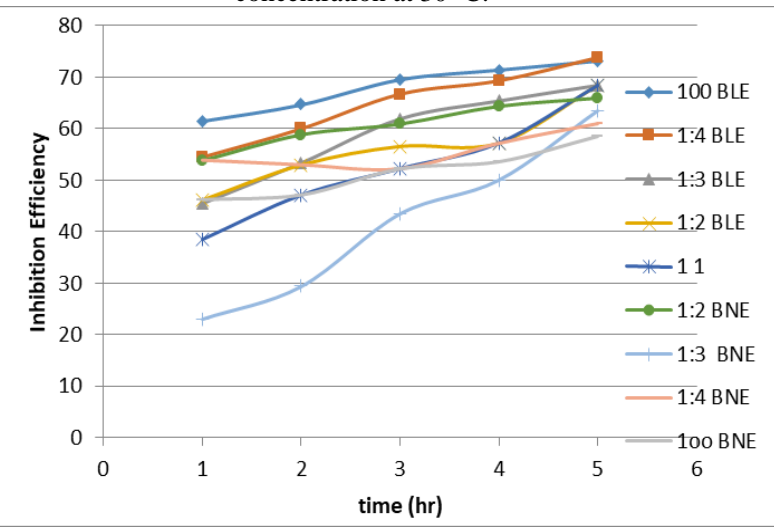

Fig. 14. Graph of Inhibition efficiency vs time for $0.3 \mathrm{~g} / \mathrm{l}$ inhibitor concentration at $40^{\circ} \mathrm{C}$.

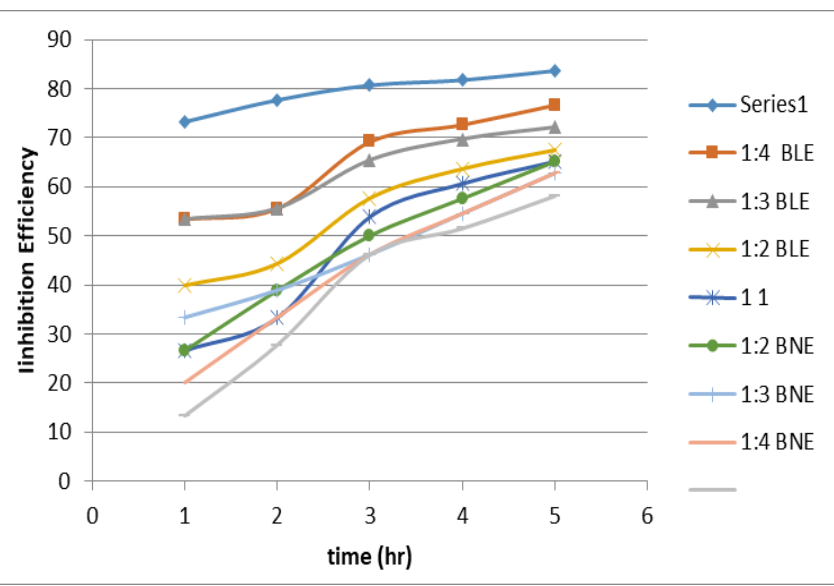

Fig. 15. Graph of Inhibition efficiency vs time for $0.3 \mathrm{~g} / \mathrm{l}$ inhibitor concentration at $50^{\circ} \mathrm{C}$. 


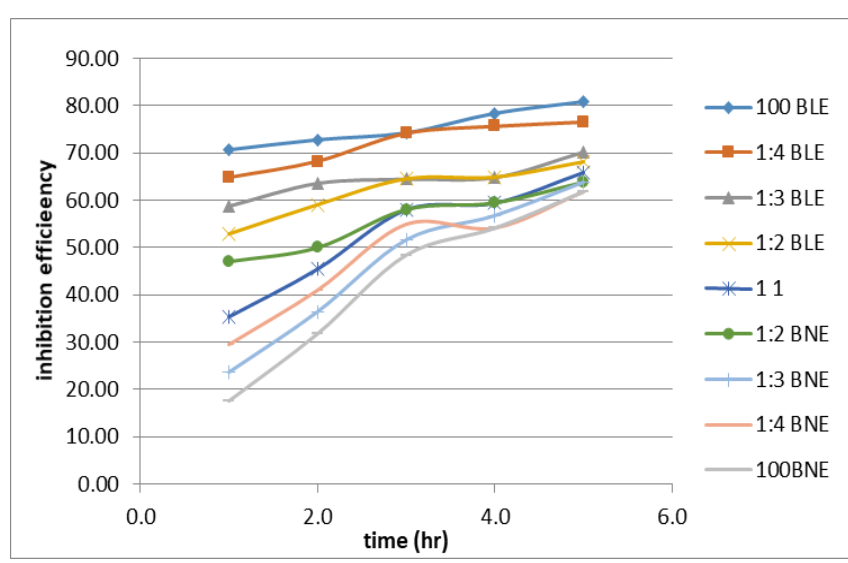

Fig. 16. Graph of Inhibition efficiency vs time for $0.5 \mathrm{~g} / \mathrm{l}$ inhibitor concentration at $30^{\circ} \mathrm{C}$

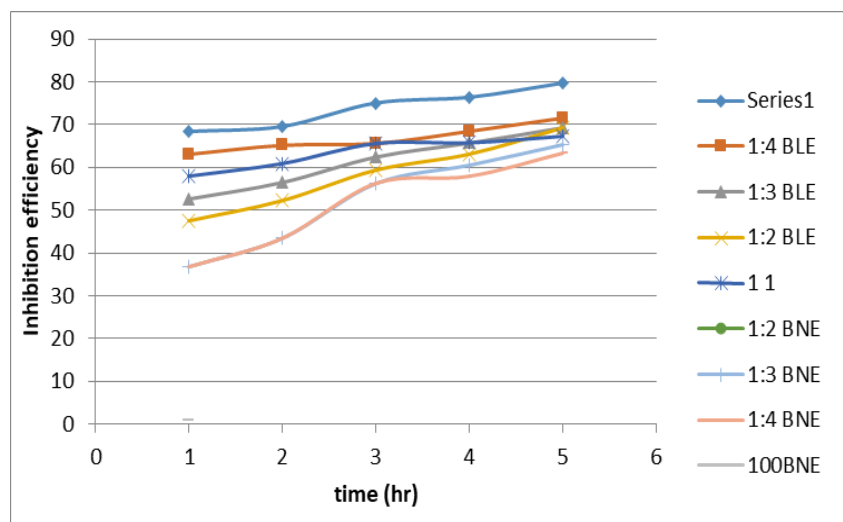

Fig. 17. Graph of Inhibition efficiency vs time for $0.5 \mathrm{~g} / \mathrm{l}$ inhibitor concentration at $40^{\circ} \mathrm{C}$

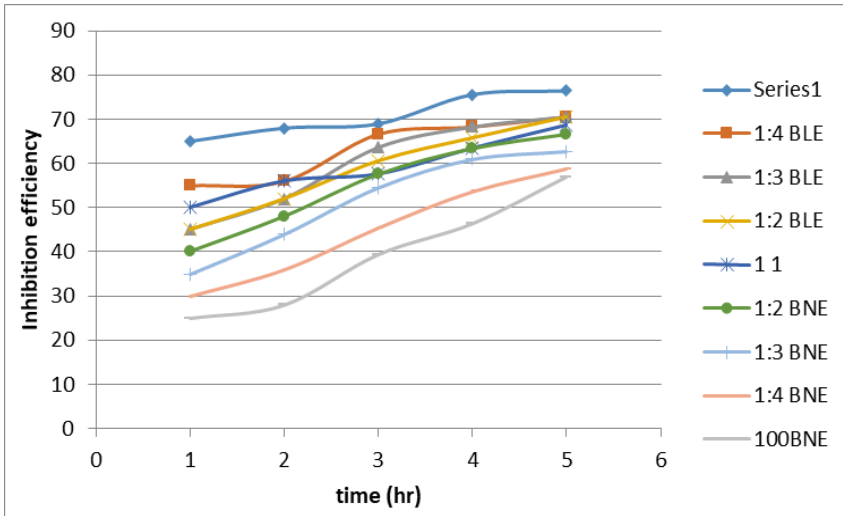

Fig. 18. Graph of Inhibition efficiency vs time for $0.5 \mathrm{~g} / \mathrm{l}$ inhibitor

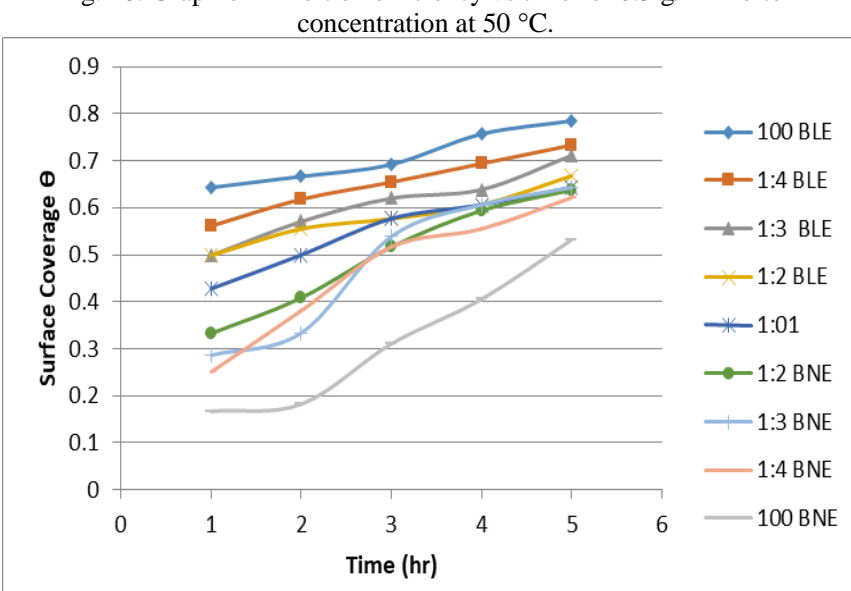

Fig. 19.Graph of surface coverage vs time for $0.1 \mathrm{~g} / \mathrm{l}$ inhibitor concentration at $40^{\circ} \mathrm{C}$.

\section{A. Effect of Temperature on Corrosion Rate}

The effect of temperature on the corrosion rate of mild steel in plain acidic medium and the presence of different concentrations of the inhibitor was studied in the temperature range of $30^{\circ} \mathrm{C}$ to $50{ }^{\circ} \mathrm{C}$. As shown in Fig. 1-9, it was observed that the rate of corrosion of mild steel in plain acid solution increases with an increase in temperature. However, the corrosion rate is much decreased for the inhibited acid solution than in the free acid solution. This shows that as temperature increases, the rate of corrosion of mild steel also increases as a result of the increase in the average kinetic energy of the reacting molecules. The decrease in the corrosion rate for the inhibited acid solution is as a result of the mitigating effect of the plant extract on the corrosion rate of the mild steel.

\section{B. Effect of Temperature on Inhibition Efficiency}

The effect of an increase in temperature on the inhibition efficiency of the mixture of Vernonia amygdalina and Musa sapientum extract is shown in Fig. 10-18. It was observed that as the reaction temperature increases from $30{ }^{\circ} \mathrm{C}$ to $50{ }^{\circ} \mathrm{C}$, the inhibition efficiency of the mixture of Vernonia amygdalina and Musa sapientum extract on the mild steel also decreases suggesting an increase in the corrosion rate. Previous investigators showed that the corrosion rate increases with an increase in temperature, which results in a decrease in the inhibition efficiency, Therefore, decreasing the reaction temperature favours the inhibition efficiency of acid extracts of the mixture of Vernonia amygdalina and Musa sapientum on mild steel in hydrochloric acid [10][18].

\section{Effect of Concentration on Inhibition Efficiency}

The inhibition efficiency of the extracts on the mild steel increases with the increasing concentration of the plant extracts as shown in Fig. 10 to 18. This is expected because as the concentration of the plant extracts increases, the fraction of the surface covered by the adsorbed molecule also increases which results in an increase in the inhibition efficiency. The inhibition efficiency increases progressively as the concentration of the extracts increases up to about $4 \%$, above which, further increase in extract concentration did not cause any significant change in the performance of the extracts. However, the inhibition efficiency decreases with an increase in the temperature of the reaction medium. The maximum percentage inhibition of $88.50 \%$ was achieved $30{ }^{\circ} \mathrm{C}$. [13]-[18].

The results showed that the corrosion rate of mild steel in $1 \mathrm{M} \mathrm{HCl}$ decreases with an increase in the concentration of the extracts and the values were in the range $100 \mathrm{BLE}, 1: 4$ BLE 1:3 BLE, 1:2 BLE, $50 \%$ BNE + 50 \% BLE, 1:2 BNE, 1:3 BNE, 1:4 BNE, 100BNE. The results obtained showed that 100 BLE has the highest corrosion inhibition capacity; this was followed by 1:4 BLE and by 1:3 BLE. The results also showed $100 \%$ BNE has the lowest inhibitory capacity when compared with 100BLE. However, the inhibitory tendencies of Banana stem (Musa genus) extract increase with the concentration of Bitter leaf (Vernonia amygdalina) in the extract. Thus, 1:4 BNE has a better inhibitory potential than 100\%BNE. Also, 1:2 BNE has higher inhibitory efficiency than 1:3 BNE. It is also observed that 
inhibition efficiency increases progressively as the concentration of the extracts increases from $0.1 \mathrm{~g} / 1$ to $0.5 \mathrm{~g} / 1$ of the extracts. It is noted that the inhibition efficiency depends on temperature and decreases with the rise of temperature. As temperature increases from $303 \mathrm{~K}$ to $323 \mathrm{~K}$, inhibitory efficiency decreases as the temperature increases. The inhibitory efficiency at $303 \mathrm{~K}$ is higher than inhibition efficiency at $313 \mathrm{~K}$. However, the corrosion rate increases as temperature increases. Thus, corrosion rate at $313 \mathrm{~K}$ is higher than the corrosion rate at $303 \mathrm{~K}$.

\section{Analysis of FTIR Spectra}

The FTIR analysis was carried out using FTIR scientific equipment for modern laboratory with model number Nicolet iS10 FT-IR Spectrometer. The FTIR spectra of $V$. amygdalina leaf extract, Musa genus leaf extract and the mixture of the two in equal proportion are shown in Fig. 20 to Fig. 22. The samples were extracted using ethanol, hence the presence of ethanol band in the spectra. The characteristic ethanol band which shows the stretching vibration of $\mathrm{O}-\mathrm{H}$ group or $\mathrm{O}-\mathrm{H}$ wagging of phenolic compounds was observed at $3419.19 \mathrm{~cm}^{-1}, 3430.17 \mathrm{~cm}^{-1}$ and $3458.21 \mathrm{~cm}^{-1}$ for $100 \mathrm{BLE}, 100 \mathrm{BNE}$ and $50 \% \mathrm{BNE}+$ $50 \%$ BLE respectively. This strongly suggested the presence of phenolic compounds in the extracts. The observed band at $2929.76 \mathrm{~cm}^{-1}$ for $100 \mathrm{BLE}$ was due to stretching vibrations of $\left(\mathrm{CH}_{2}\right)$ in $\mathrm{CH}_{2} \mathrm{OH}$ group the bands were observed at $2966 \mathrm{~cm}^{-1}$ for $100 \mathrm{BNE}$ and at $2929.80 \mathrm{~cm}^{-1}$ for $50 \% \mathrm{BNE}+50 \%$ BLE.

The observed bands at $2929.76 \mathrm{~cm}^{-1}$ in $100 \mathrm{BLE}$, $2966.00 \mathrm{~cm}^{-1}$ in $100 \mathrm{BNE}$ and $2929.80 \mathrm{~cm}^{-1}$ in $50 \% \mathrm{BNE}+$ $50 \% \mathrm{BLE}$ is due to stretching vibration of $\mathrm{CH}_{2}$ group. A band at $1628.72 \mathrm{~cm}^{-1}$ in $100 \mathrm{BLE}, 1686.39 \mathrm{~cm}^{-1}$ in $100 \mathrm{BNE}$ and $1639.00 \mathrm{~cm}^{-1}$ in $50 \% \mathrm{BNE}+50 \% \mathrm{BLE}$ is due to stretching vibrations of $\mathrm{C}=\mathrm{C}$ groups, aromatic ring deformation and the presence of flavonoids and amino acids. The identified band at $1079.70 \mathrm{~cm}^{-1}$ in 100BLE, $1077.61 \mathrm{~cm}^{-1}$ in 100BNE and $1052.21 \mathrm{~cm}^{-1}$ in $50 \% \mathrm{BNE}+$ $50 \% \mathrm{BLE}$ is due to the presence of $\mathrm{C}-\mathrm{O}$ stretching ester group or secondary alcohols. Therefore, the functional group shown on the FTIR analysis confirmed the presence of flavonoid, saponins, and tannins in Bitter leaf (Vernonia amygdalina) and Banana stem (Musa genus) extracts. [20], [11].

From the spectra shown in Fig. 20-22, the observed functional groups in the $100 \%$ ethanolic extract of $V$. amygdalina leaf, $100 \%$ Musa genus and $50 \% \mathrm{BNE}+50 \%$ BLE show the presence of amino acids, lipids, phenolic compounds, flavonoids, carbohydrates, saponins, and tannins. The presence of tannins in the extracts is one of the factors responsible for inhibitory property of the extracts. [5], [16], [17].

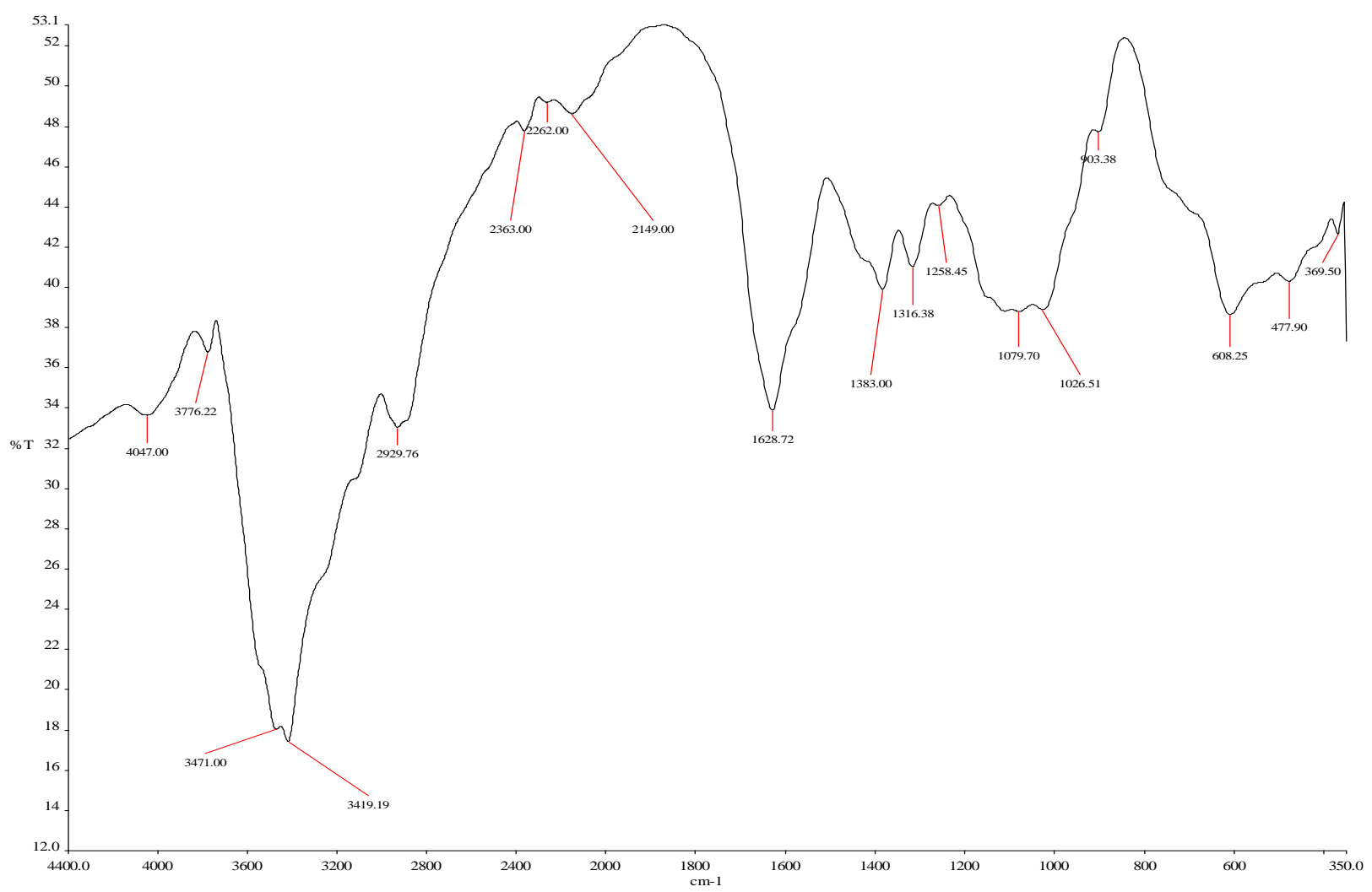

Fig. 20. FTIR spectra of $100 \%$ Bitter Leaf Extract (100\% BLE). 


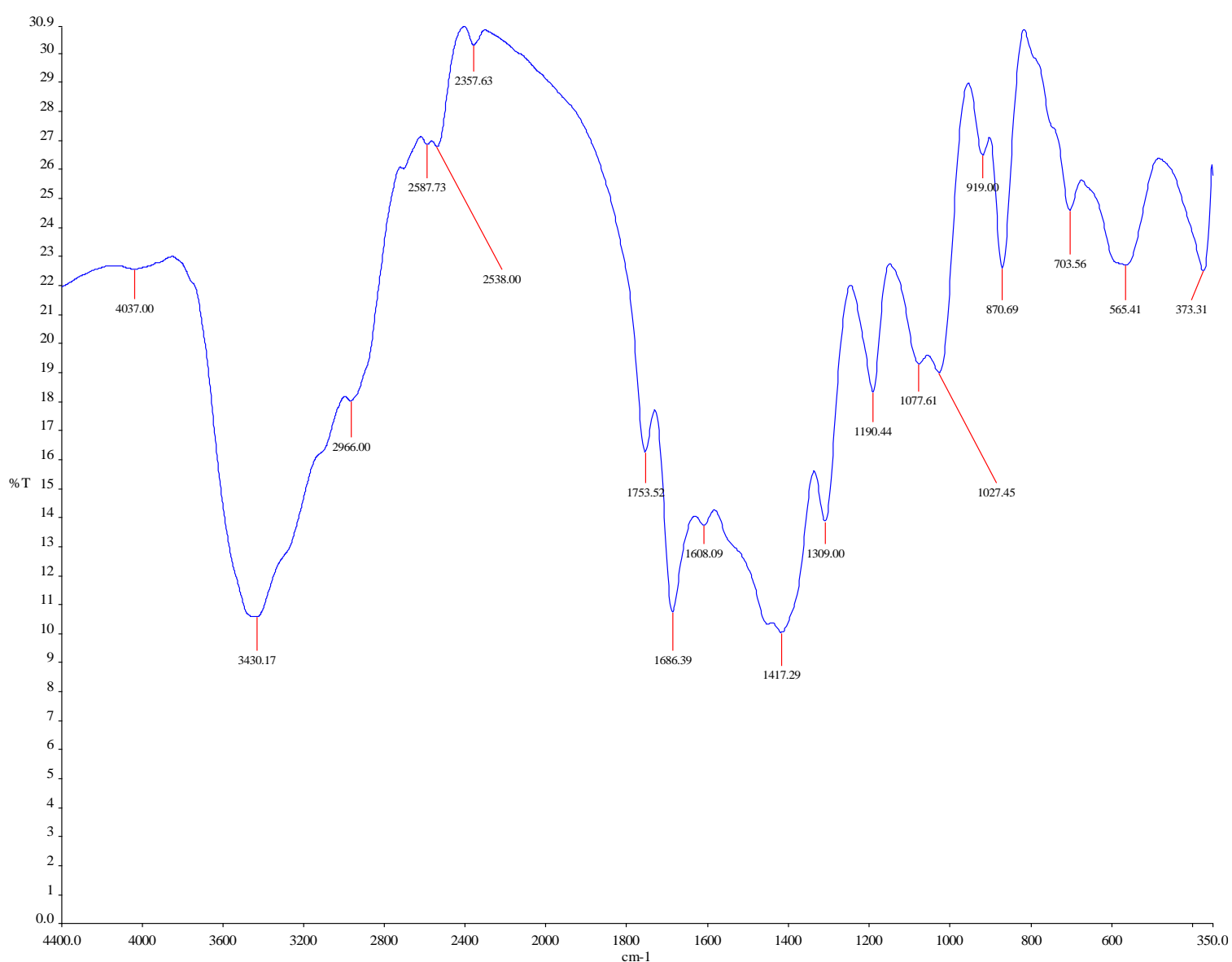

Fig. 21. FTIR spectra of $100 \%$ Banana Stem Extract (100\% BNE).

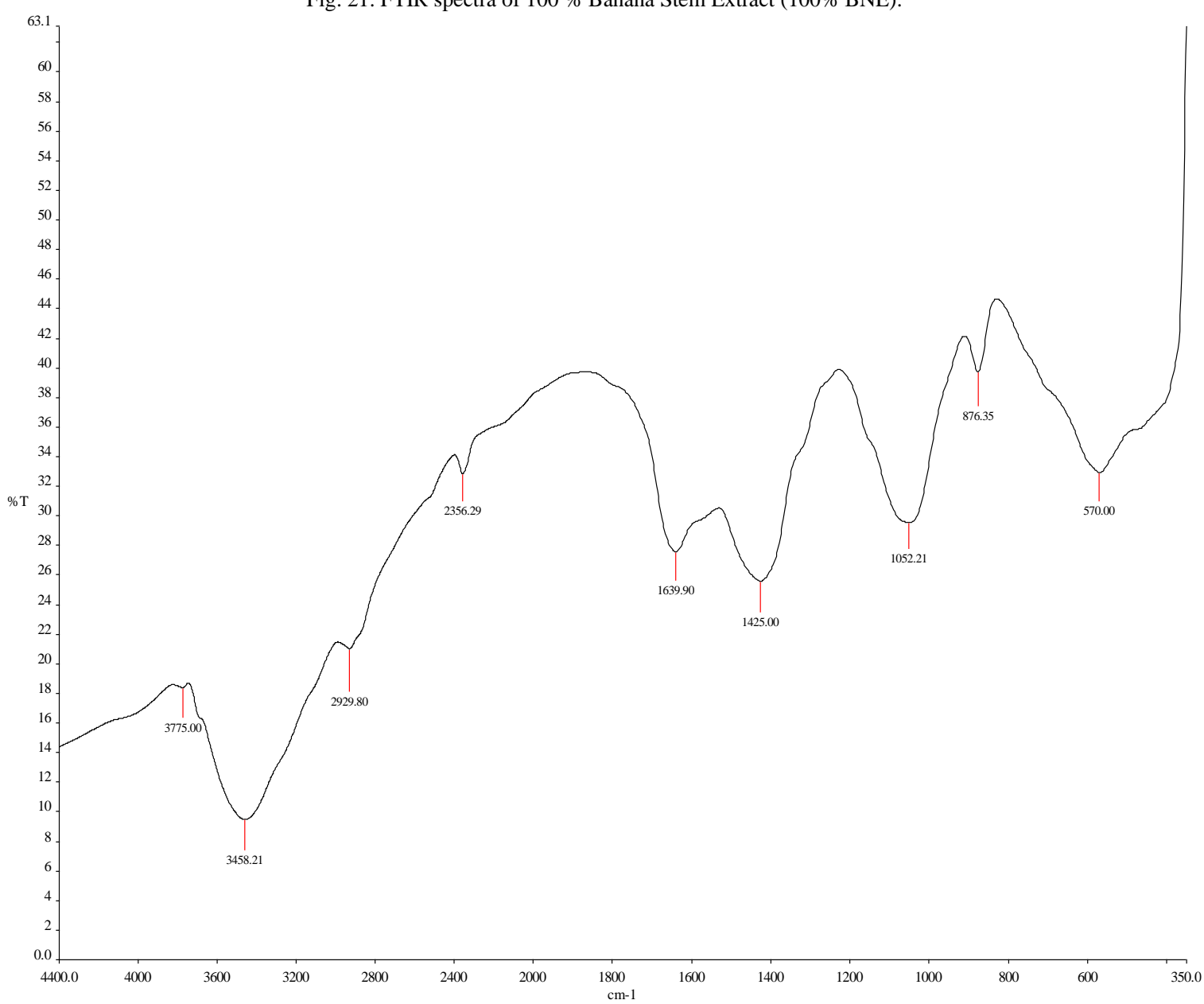

Fig. 22. FTIR spectra of ratio 1:1 (50\% BNE + 50 \% BLE). 


\section{E. Surface Morphology of Mild Steel}

The surface analysis was carried out using SEM for the mild steel surface immersed in 1M HCL solution in the absence of inhibitor and then in the presence of $50 \mathrm{mg} / \mathrm{L}$ of inhibitor. The SEM images of the mild steel in 1M HCL without inhibitor and with inhibitor are shown in Plate 1 and Plate 2, respectively. It was observed that there is a significant distinction surface structure of the mild steel for the uninhibited and inhibited for different extracts with the damage or rapid oxidized effect shown on the uninhibited acidic medium. The SEM images clearly indicate that the mild steel, which was immersed in $1 \mathrm{M} \mathrm{HCl}$ solution, indicates that the surface is highly corroded while the mild steel surface was protected from corrosion in the presence of plant extracts which is acting as a corrosion inhibitor. The presence of the inhibitor at the optimum concentration exhibits a smooth surface indicating high restricted corrosion [17], [18].

This shows that the mixture of $V$. amygdalina leaf and $M$. acuminate extract inhibits corrosion of mild steel in $1 \mathrm{M}$ HCL solution. These results are in good agreement with the other methods like electrochemical and weight loss measurement.[11], [12], [23], [24].

\section{F. Eds Analysis}

The Energy Dispersive X-ray Spectroscopy (EDS) shows the elemental analysis of mild steel before and after corrosion study. The EDS compositional analysis results obtained from the spectra show a weight percent of Carbon (5.0 wt \%), Oxygen (14.4 wt \%), Iron (54.20 wt \%), Copper (1.70 wt \%), and Chromium (20.0 wt \%) for the mild steel before corrosion experiment. However, after corrosion, the result revealed a weight percent of Carbon (5.20 wt \%), Oxygen (17.90 wt \%), Iron (56.20 wt \%), Chromium (19.10 wt \%), and Copper (1.60 wt \%). Plate 3 and Plate 4 indicate that Iron has the highest peak in the EDS spectra for both mild steel coupon samples. It is clear from the EDS spectra of the mild steel that the composition of Carbon and Oxygen increased by $4 \%$ and $24.31 \%$ respectively. This increase could be attributed to the presence of $\left(\mathrm{CH}_{2}\right)$ in $\mathrm{CH}_{2} \mathrm{OH}$ group that occurred due to stretching vibrations at $2929.76 \mathrm{~cm}^{-1}$ in the FTIR spectra. However, there was a deceased in the composition of copper before corrosion and after corrosion by $5.88 \%$. [16]-[18].

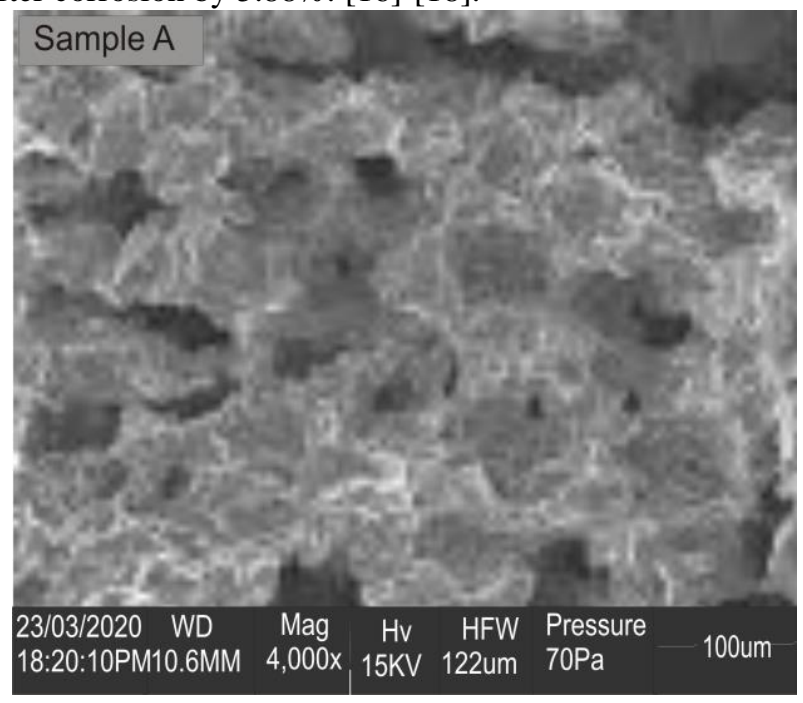

Plate 1. SEM image of mild steel before corrosion X4,000

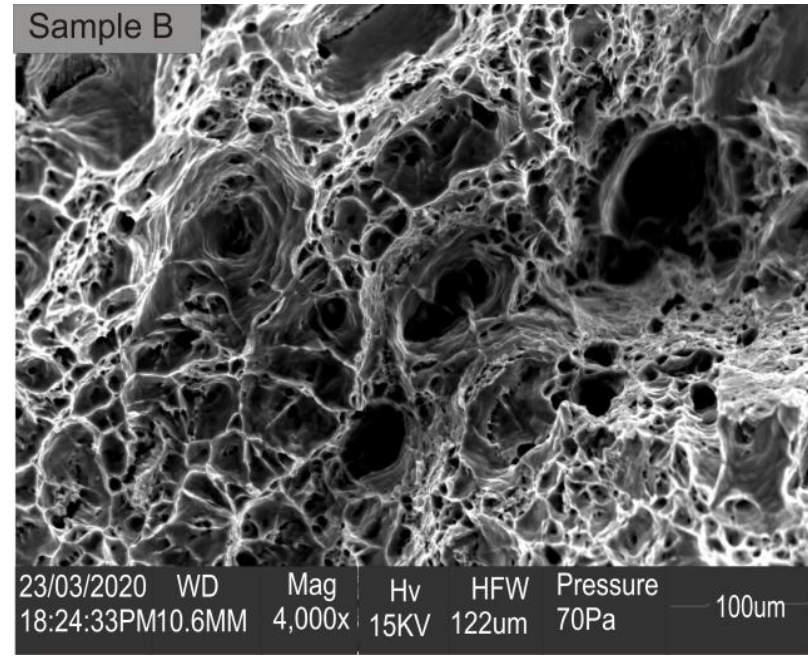

Plate 2. SEM image of mild steel after corrosion X4,000.

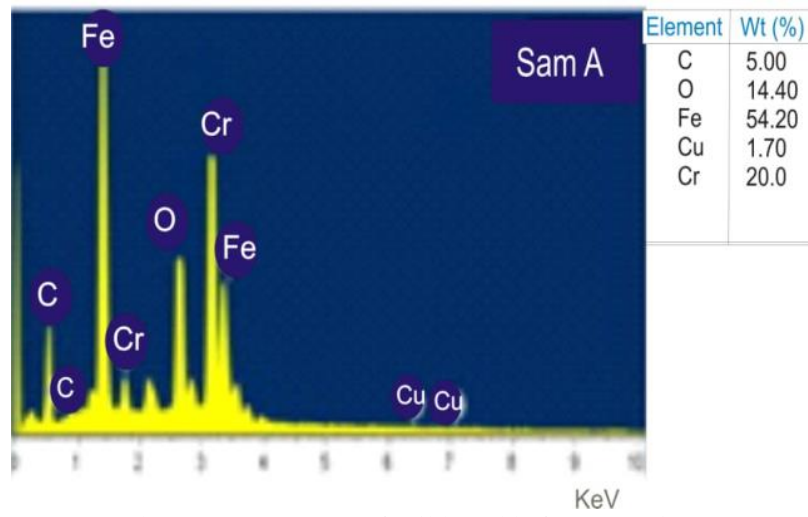

Plate 3. EDS Spectra of Mild steel before corrosion.

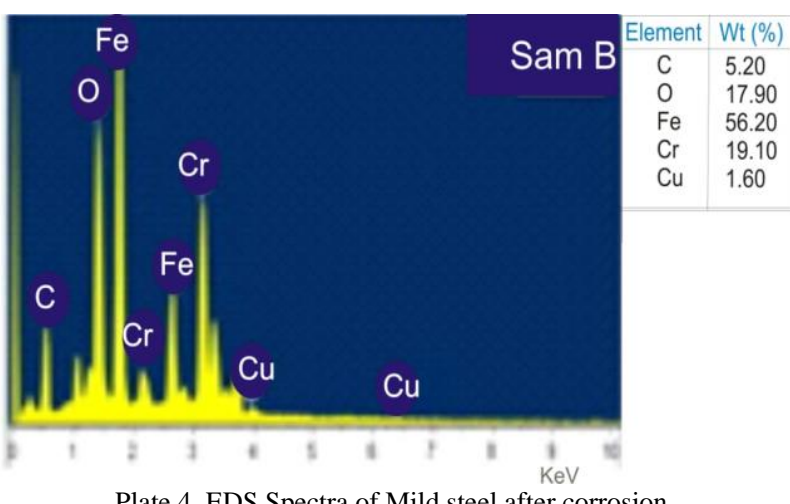

Plate 4. EDS Spectra of Mild steel after corrosion

\section{CONCLUSION}

The result of this research shows that the leave extract for Bitter leaf (Vernonia amygdalina) and Banana stem (Musa Acuminata) inhibits the corrosion of mild steel in $\mathrm{HCl}$ depending on the concentration. $100 \%$ BLE proved to have the highest corrosion inhibition effectiveness for different concentrations of the extracts and for all the ranges of temperature used. The $100 \mathrm{BNE}$ inhibited much lower corrosion inhibitory effectiveness when compared with 100 $\%$ BLE. The inhibitory efficiency of the extracts follows the following order: 100BLE $>1: 4 \quad$ BLE $>1: 3 \quad$ BLE $>1: 2$ BLE $>1: 1>1: 2$ BNE $>1: 3$ NE $>1: 4$ BNE $>100 B N E$.

The inhibition efficiency increases with an increase in the concentration of the extracts but decreases with the rise of temperature, indicating that at the higher temperature, dissolution of mild steel predominates on the surface. 
The ethanolic extracts of Bitter leaf (Vernonia amygdalina) and Banana stem (Musa Acuminata) contain various phytochemical components such as Tannin, saponin, and flavonoids, which are the major components in the extract responsible for the inhibitory properties exhibited by the extracts but Bitter leaf (Vernonia amygdalina has more phytochemical constituents.

SEM images of mild steel in the absence of inhibitor show clear pits and cavities due to strong damages by the attack of $\mathrm{HCl}$. However, micrographs in the presence of inhibitors show less damage to the surface of the mild steel. This shows that the extracts from Bitter leaf (Vernonia amygdalina) and Banana stem (Musa Acuminata) extracts have corrosion inhibitory potentials. Relatively, Bitter leaf (Vernonia amygdalina) extract blend showed greater inhibitory potentials.

\section{REFERENCES}

[1] O. I. Sekunowo, S. I. Durowaye, and G. I. Lawal, Potentio-dynamic Corrosion Study of Mild Steel in Seawater and 1M HCl. NSE Technical Transaction, 2017;51(1): 85-91.

[2] L.L. Shreir, Corrosion, Metal/Environmental Reaction, NewnesButterworths, London, UK, 1976, vol. 1, pp 1-6.

[3] V.S. Sastri, Green Corrosion Inhibitors: Theory and Practice, First Edition. John Wiley \& Sons, Inc. Published 2011 by John Wiley \& Sons, Inc, 2011.

[4] P. Rostron and S. Kasshanna, Novel Synthesis of Vegetable Oil Derived Corrosion Inhibitors. International Journal of Corrosion, 2015;2015:1-6.

[5] A. Ostovari, S. M. Hoseinieh, M. Peikari, S. R. Shadizadeh and S. J Hashemi, Corrosion inhibition of mild steel in 1M HCL solution by henna extract: A comparative constituent (lawsone, Gallic acid $\alpha$-DGlucoseand Tannic acid). Journal of Corrosion Science, 2009:51(9):1935-1949.

[6] A. Rani and J. B. Bharathi, Green inhibitors for protection of metals and alloys. International Journal of corrosion, 2012;20: 12-15.

[7] K. S. Okiongbo and G. Ogobiri, Predicting Soil Corrosivity along a Pipeline route in the Niger Delta Basin Using Geoelectrical Method. Implication for Corrosion Control Engineering 5:237-244, 2013.

[8] N. O. Eddy, E. E. Ebenso and A. O Odiongenyi, Corrosion inhibitive properties and adsorption behaviour of ethanol extract of piper guinensis as a green corrosion inhibitor for mild steel in $\mathrm{H}_{2} \mathrm{SO} 4$ African Journal of Pure and Applied Chemistry, 2008;2(11):107-115.

[9] M. A. Ameer and A. M Fekry, Corrosion inhibition of mild steel by natural product compound. Progress in Organic Coatings, 2011;71: 343-349.

[10] I. C. Awe, A. S. Abdulrahaman, H. K. Ibrahim, A. G. Kareem and S M. Adams, Inhibitive Performance of Bitter Leaf Root Extract on Mild Steel Corrosion in Sulphuric Acid Solution. American Journal of Materials Engineering and Technology, 2015;3(2): 35-45.

[11] J. H Doughari, Phytochemical: Extraction Methods, Basic Structures and Mode of Action as Potential Chemotherapeutic Agents, Phytochemical - A Global Perspective of Their Role in Nutrition and Health, 2012.

[12] T. J. Tuaweri, E. A. Ogbonnaya and O.O. Onyemaobi, Corrosion Inhibition of Heat Treated Mild Steel with Neem Leave Extract in a Chloride Medium. International Journal of Research in Engineering and Technology, 2015;4(6): 404-409.

[13] B. S. Prathibha, P. Kotteeswaran and V.B Raju, Study on the inhibition of mild steel corrosion by N, N-dimethyl-N-(2phenoxyethyl)dodecan-1-aminiumbromide in $\mathrm{HCl}$ medium, IOSR Journal of Applied Chemistry media. Journal of chil. Chem. Soc., 2015;52:1206

[14] G. E. Debi, H. Esah, I. Mohammed, A. S. Abdulrahman and M. Aminu, Effect of Vernonia Amygdalina Extract on Corrosion Inhibition of Mild Steel in Simulated seawater. Australian Journal of basic and Applied Sciences, 2013;7(14): 257-263.

[15] K .F. K. Oyedeko, M. O. Omidiji. .O Akinyemi and A. Adesina, Use of vernonia amygdalina (bitter leaf) for Corrosion Inhibition of Mild Steel in Sea Water, LASU Journal of Engineering, Science and Technology, 2019; 1(2).
[16] T. Seth, A. Chaturved, R. K. Updhyay and S. P. Mathur, Corrosion inhibitory effects of some schiffs bases on mild steel in acidic medium, 2007;52(3):1206-1213.

[17] G. N. Chukwueze and N.A.G. Aneke, Comparative analysis of corrosion inhibition of mild steel using pawpaw and Neem Leaves extracts in Sulphuric acid medium. International Journal of Novel Research in Physics Chemistry \& Physics, 2019;6(3):7-13.

[18] O. O. Obiukwu, I. O. Opara and B. C. Oyinna, Corrosion Inhibition of Stainless Steel Using Plant Extract Vemonia amygdalina and Azadirachta indica. Pacific Journal of Science and Technology, 2013; 14(2): 31-35. 